Article

\title{
Reactions of an Isolable Dialkylsilylene with Aroyl Chlorides. A New Route to Aroylsilanes
}

\author{
Xu-Qiong Xiao, Xupeng Liu, Qiong Lu, Zhifang Li *, Guoqiao Lai and Mitsuo Kira * \\ Key Laboratory of Organosilicon Chemistry and Material Technology of Ministry of Education, \\ Hangzhou Normal University, Hangzhou 311121, China; xqxiao@hznu.edu.cn (X.-Q.X.); \\ lxpyoujigui@163.com (X.L.); ahbzmclq@163.com (Q.L.); gqlai@hznu.edu.cn (G.L.) \\ * Correspondence: zhifanglee@hznu.edu.cn (Z.L.); mkira@m.tohoku.ac.jp (M.K.); Tel.: +86-571-2886-7825 (Z.L.) \\ Academic Editor: Derek J. McPhee \\ Received: 14 September 2016; Accepted: 8 October 2016; Published: 15 October 2016
}

\begin{abstract}
The reactions of isolable dialkylsilylene 1 with aromatic acyl chlorides afforded aroylsilanes 3a-3c exclusively. Aroylsilanes 3a-3c were characterized by ${ }^{1} \mathrm{H}-,{ }^{13} \mathrm{C}-$, and ${ }^{29} \mathrm{Si}-\mathrm{NMR}$ spectroscopy, high-resolution mass spectrometry (HRMS), and single-crystal molecular structure analysis. The reaction mechanisms are discussed in comparison with related reaction of $\mathbf{1}$ with chloroalkanes and chlorosilanes.
\end{abstract}

Keywords: dialkylsilylene; silyl ketone; acylsilane; insertion; X-ray analysis

\section{Introduction}

Acylsilanes or $\alpha$-silyl ketones have been known as a unique class of silicon compounds [1-9], showing remarkably red-red shifted $n \rightarrow \pi^{*}$ transition bands [1,2] and being useful as distinct reagents in organic synthesis [4-6,10-19]. Most of all, acyltris(trimethylsilyl)silanes are of particular importance, which were utilized for the synthesis of the first stable silicon-carbon doubly bonded compounds (silenes) [20,21]. However, the synthesis of acylsilanes is still limited because of the relatively facile silicon-carbon bond cleavage under the reaction conditions. The direct reaction of a silylmetal with an acyl halide afforded the corresponding acylsilanes, but the yields were usually low due to the undesired secondary reactions [22,23]. The oxidation of $\alpha$-silyl alcohols using ordinary oxidizing reagents often leads to the corresponding aldehydes [5]. The first successful synthesis of an aroylsilane was achieved by using an elaborate two-step route in good yields (Equation (1)) [22], while it is not applicable for the synthesis of alkanoylsilanes.

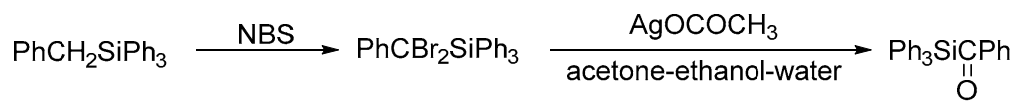

The dithiane route applicable for the synthesis of a wider range of acylsilanes was studied by Brook et al. [24] and Corey et al. [25] at the same time in 1967 (Equation (2)). The defect of the method is the use of a toxic mercury compound for the hydrolysis of the silylated dithianes.

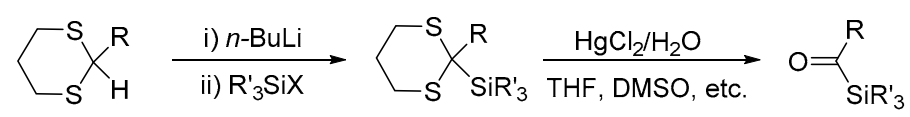


A variety of acylsilanes have been synthesized up to date using different methods, the reactions of protected aldehydes, esters, and other carboxylic acid derivatives, etc. with various silicon reagents [1-9].

During the course of our studies of the reactions of an isolable dialkylsilylene with various functional groups [26-30], we have found that the silylene inserts exclusively into the $\mathrm{C}-\mathrm{Cl}$ bond of aroyl chlorides providing rather exceptional aroyl(chloro)silanes that cannot be obtained via conventional methods. Very recently, an acyl(halo)silane was utilized to synthesize an isolable silenyllithium (Equation (3)) [31].

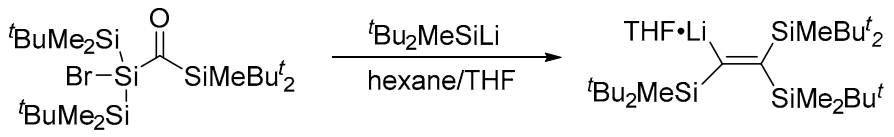

\section{Results and Discussion}

\subsection{Synthesis and Characterization}

The 1:1 reactions of dialkylsilylene 1 [32-37] with benzoyl and 4-substituted benzoyl chlorides $\mathbf{2 a}-\mathbf{2} \mathbf{c}$ at $-30{ }^{\circ} \mathrm{C}$ afforded the corresponding benzoyl(chloro)silanes $\mathbf{3 a}-\mathbf{3 c}$ in high yields, indicating that the $\mathrm{C}$ (carbonyl) $\mathrm{Cl}$ bond is much more reactive than the carbonyl group (Equation (4)) [38]. No significant difference was observed in the reactivity among benzoyl chlorides 2a-2c. Even when an excess amount of $\mathbf{1}$ was used to a benzoyl chloride (2:1 mol ratio), the corresponding benzoyl(chloro)silane was obtained solely as the product. The expected reactions of 3 with silylene $\mathbf{1}$ would be prohibited due to the steric effects of bulky silylene moiety of 3 . The reactions of 1 with alkanoyl chlorides like acetyl chloride and butanoyl chloride afforded complex reaction mixtures. Because simple alkanoyl chlorides are more reactive than aroyl chlorides, the products of the reactions between $\mathbf{1}$ and the alkanoyl chlorides may react further with $\mathbf{1}$ to give the unidentified products.

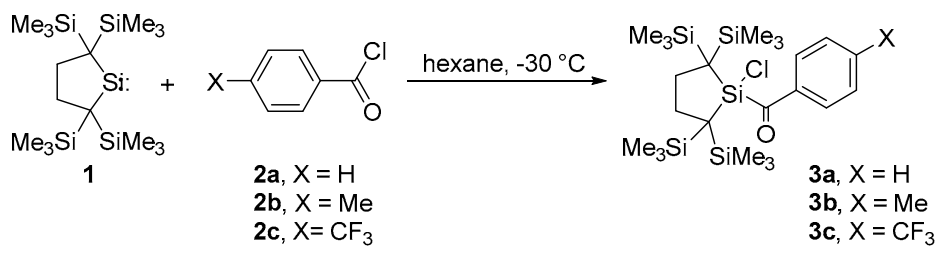

Benzoylsilanes 3a-3c, which are stable thermally with definite melting points and under moist air, were characterized by ${ }^{1} \mathrm{H}-,{ }^{13} \mathrm{C}$-, and ${ }^{29} \mathrm{Si}-\mathrm{NMR}$ spectroscopy, high-resolution mass spectrometry (HRMS), and X-ray structure analyses.

\subsection{NMR Spectroscopy}

In the ${ }^{1} \mathrm{H}-\mathrm{NMR}$ spectra of $\mathbf{3 a - 3 \mathbf { c }}$, two singlet signals due to four trimethylsilyl groups were observed in the region of $0.1-0.3 \mathrm{ppm}[0.16,0.30$ (3a); $0.17,0.29(3 \mathbf{b}) ; 0.17,0.29$ (3c) $]$, indicating that there are two types of trimethylsilyl groups because of their Cs symmetry of 3 . In accord with the observation, two TMS carbon ( $\delta$ ca. 3.2 and 4.3 ppm) and silicon signals ( $\delta$ ca. 2.8 and 5.5 ppm) were observed in the ${ }^{13} \mathrm{C}$ - and ${ }^{29} \mathrm{Si}-\mathrm{NMR}$ spectra of 3a-3c. The signals at 225.3 (3a), 224.5 (3b), and 224.8 (3c) ppm in ${ }^{13} \mathrm{C}$-NMR spectra are ascribed to the carbonyl carbon signals, which are at higher field relative to the typical acylsilanes (ca. 240 ppm) [39,40]. However, these chemical shift values are significantly lower than those for typical ketones like benzophene $(\delta 196.7)$ and acetophenone $(\delta 198.2)$, indicating 
the unique electronic feature of acylsilanes. The ${ }^{29} \mathrm{Si}-\mathrm{NMR}$ resonances due to the ring silicon of $\mathbf{3 a}-\mathbf{3 c}$ appear at the same chemical shifts of $27.8 \mathrm{ppm}$.

\subsection{Molecular Structure Analysis}

Molecular structures of compounds 3a-3c were determined by X-ray single-crystal diffraction analysis. Yellow single crystals of 3a-3c suitable for X-ray crystallography were obtained by slowly evaporating the solvent from their hexane solutions. The ORTEP drawing of compound 3a is depicted in Figure 1. Compound 3a was crystallized in space group $P_{-1}$ with two crystallographically independent molecules in an asymmetric unit. The structural parameters of the two molecules in a unit cell are similar but different in the torsion angles of $\mathrm{C}(1) \operatorname{Si}(1) \mathrm{C}(17) \mathrm{O}(1)$ and its equivalent, $\mathrm{C}(24) \mathrm{Si}(6) \mathrm{C}(40) \mathrm{O}(2),\left(129.03^{\circ}\right.$ and $5.26^{\circ}$, respectively). The sum of bond angles around $\mathrm{C}(17)$ and $C(40)$ are $360^{\circ}$, being in accord with the $s p^{2}$ character of the carbonyl carbon atom. The distances of $\operatorname{Si}(1)-C(17)(1.935(3) \AA)$ and $\operatorname{Si}(6)-C(40)$ bonds (1.929(2) Å), are significantly larger than the normal Si-C bond length (1.87-1.89 ̊). A similarly long distance of the Si-C(carbonyl) bond (1.926 ̊) has been observed in the molecular structure of acetyltriphenylsilane by Trotter et al. [41]. The origin may be ascribed to the effective $\sigma(\mathrm{SiC})-n(\mathrm{O})$ conjugation as proposed by Ramsey, Brook, Bassindale, and Bock [42]. In other words, it is suggested that resonance form $\mathbf{B}$ contributed significantly to the bonding in acylsilanes.

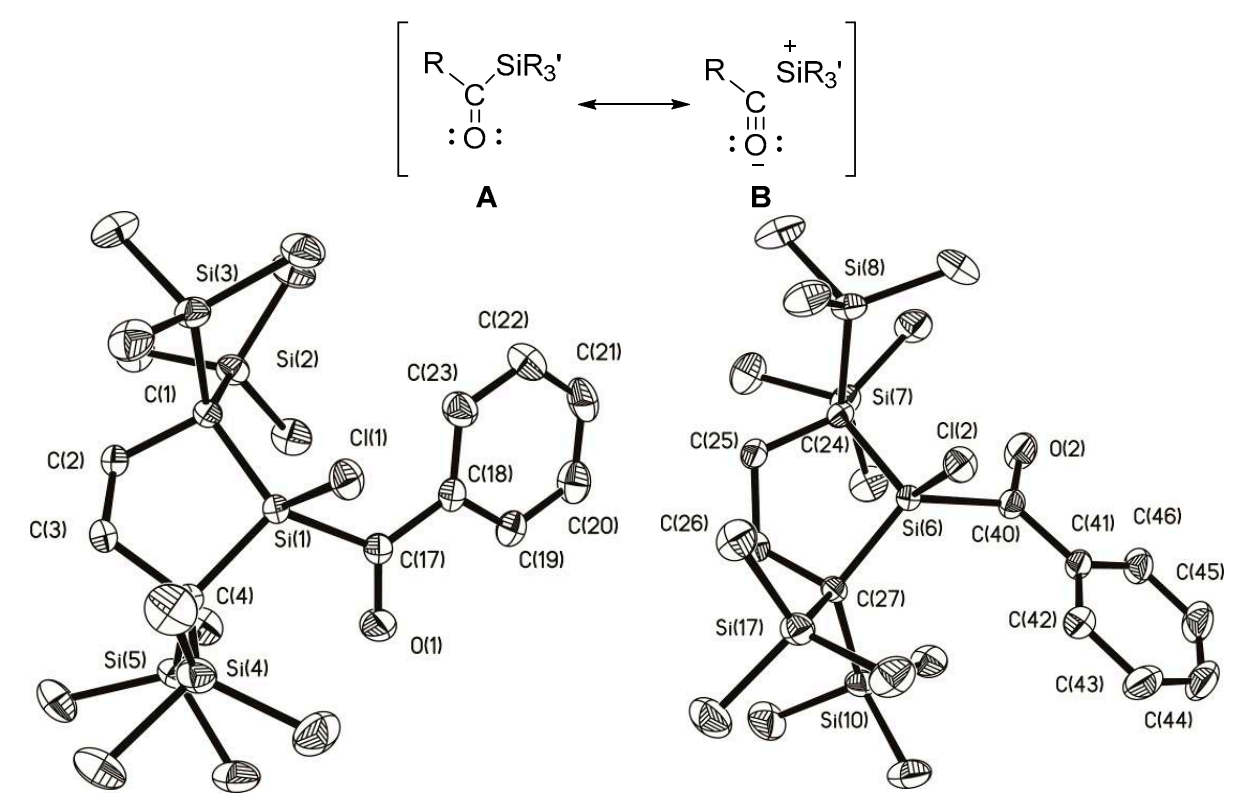

Figure 1. ORTEP drawing of the independent molecules in 3a. (Hydrogen atoms are omitted for clarity. Thermal ellipsoids are shown at the $30 \%$ probability level.) Selected bond lengths $(\AA)$ and angles $\left({ }^{\circ}\right)$ : $\mathrm{Si}(1)-\mathrm{C}(4)$ 1.877(2), $\mathrm{Si}(1)-\mathrm{C}(1)$ 1.890(2), $\mathrm{Si}(1)-\mathrm{C}(17)$ 1.935(3), $\mathrm{Si}(1)-\mathrm{Cl}(1)$ 2.1006(9), $\mathrm{O}(1)-\mathrm{C}(17)$ 1.223(3), $\mathrm{Si}(6)-\mathrm{C}(24)$ 1.882(2), Si(6)-C(27) 1.889(2), Si(6)-C(40) 1.929(2), Si(6)-Cl(2) 2.1001(9), $\mathrm{O}(2)-\mathrm{C}(40)$ 1.227(3); C(4)-Si(1)-C(1) 102.55(11), C(17)-Si(1)-Cl(1) 95.66(9), O(1)-C(17)-C(18) 120.2(2), $\mathrm{O}(1)-\mathrm{C}(17)-\mathrm{Si}(1)$ 114.54(19), C(18)-C(17)-Si(1) 125.21(17), C(24)-Si(6)-C(27) 102.25(11), C(40)-Si(6)-Cl(2) 96.14(8), O(2)-C(40)-C(41) 119.4(2), O(2)-C(40)-Si(6) 114.64(18), C(41)-C(40)-Si(6) 125.89(17).

Similarly, compounds $\mathbf{3} \mathbf{b}$ and $3 \mathbf{c}$ were crystallized in space group $P 21 / n$ and $P-1$ and their molecular structures are shown in Figures 2 and 3 . A single crystal of $\mathbf{3 b}$ has two crystallographically independent molecules in the asymmetric unit, while that of $3 \mathrm{c}$ has one independent molecule. Their structural parameters are similar to those of $\mathbf{3 a}$. 

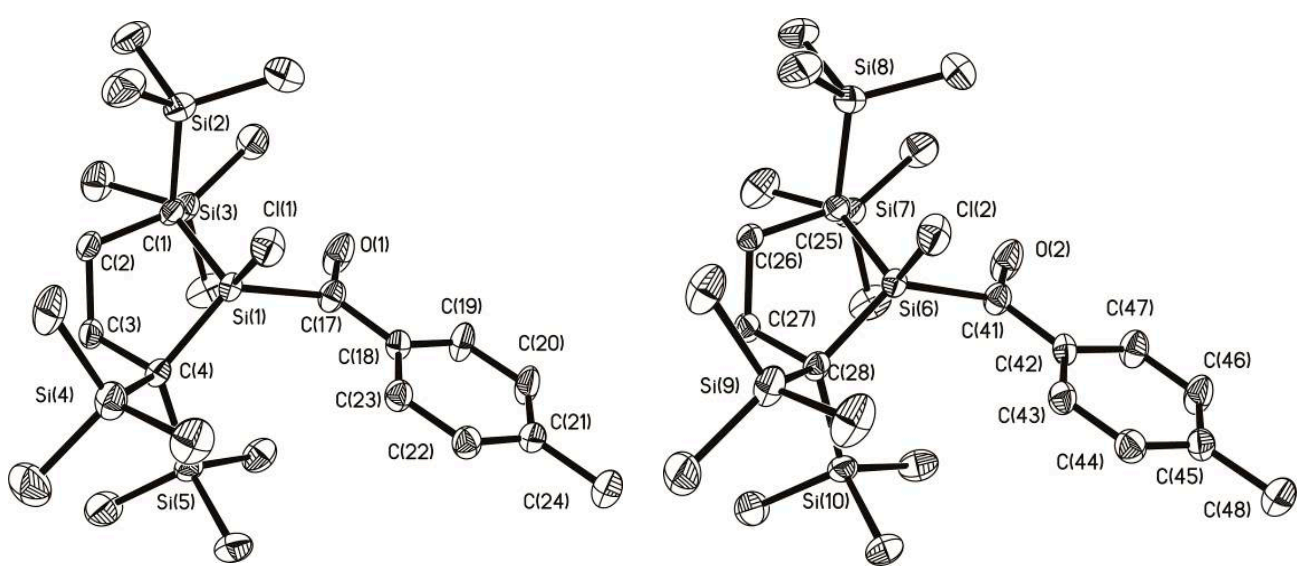

Figure 2. ORTEP drawing of the independent molecules in 3b. (Hydrogen atoms are omitted for clarity. Thermal ellipsoids are shown at the $30 \%$ probability level.) Selected bond lengths $(\AA)$ and angles $\left({ }^{\circ}\right)$ : $\mathrm{Si}(1)-\mathrm{C}(1)$ 1.883(4), $\mathrm{Si}(1)-\mathrm{C}(4)$ 1.898(4), $\mathrm{Si}(1)-\mathrm{C}(17)$ 1.940(4), $\mathrm{Si}(1)-\mathrm{Cl}(1) 2.1003(14)$, $\mathrm{C}(17)-\mathrm{O}(1)$ 1.223(5), $\mathrm{Si}(6)-\mathrm{C}(28)$ 1.888(4), Si(6)-C(25) 1.887(4), Si(6)-C(41) 1.927(4), Si(6)-Cl(2) 2.0967(15), $\mathrm{C}(41)-\mathrm{O}(2)$ 1.216(5); C(1)-Si(1)-C(4) 102.26(17), C(17)-Si(1)-Cl(1) 97.97(13), O(1)-C(17)-C(18) 119.7(4), $\mathrm{O}(1)-\mathrm{C}(17)-\mathrm{Si}(1)$ 113.2(3), C(18)-C(17)-Si(1) 126.9(3), C(28)-Si(6)-C(25) 102.12(16), C(41)-Si(6)-Cl(2) 98.33(14), O(2)-C(41)-C(42) 119.1(4), O(2)-C(41)-Si(6) 114.4(3), C(42)-C(41)-Si(6) 126.3(3).

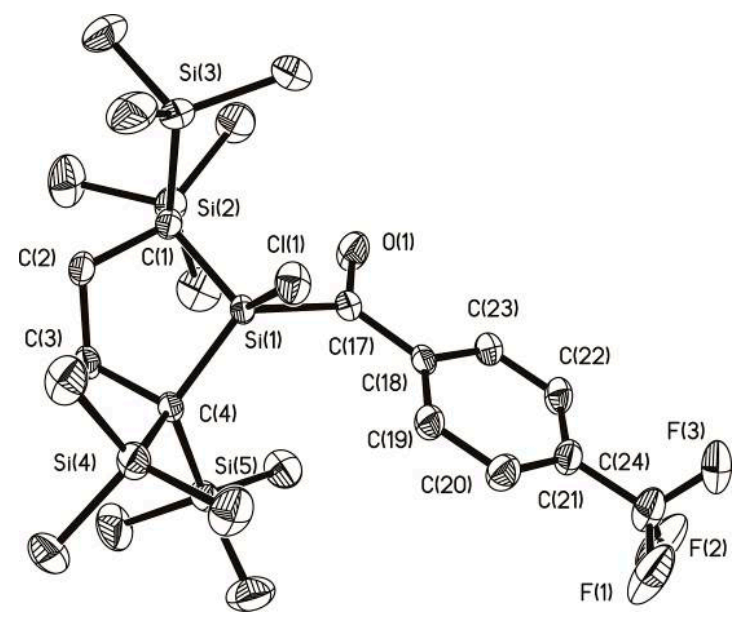

Figure 3. ORTEP drawing of compound 3c. (Hydrogen atoms are omitted for clarity. Thermal ellipsoids are shown at the $30 \%$ probability level.) Selected bond lengths $(\AA)$ and angles $\left({ }^{\circ}\right)$ : $\operatorname{Si}(1)-\mathrm{C}(1)$ 1.8789(17), $\mathrm{Si}(1)-\mathrm{C}(4)$ 1.8850(16), $\mathrm{Si}(1)-\mathrm{C}(17)$ 1.9364(19), $\mathrm{Si}(1)-\mathrm{Cl}(1) 2.1029(7), \mathrm{C}(17)-\mathrm{O}(1)$ 1.217(2); $\mathrm{C}(1)-\mathrm{Si}(1)-\mathrm{C}(4)$ 102.20(7), C(17)-Si(1)-Cl(1) 7.03(6), O(1)-C(17)-C(18) 18.54(16), O(1)-C(17)-Si(1) 15.19(14), C(18)-C(17)-Si(1) 126.03(13).

\subsection{Mechanistic Aspects}

Because the insertion of silylene 1 into $\mathrm{C}-\mathrm{Cl}$ [43-48] and $\mathrm{Si}-\mathrm{Cl}$ [48-53] bonds have been reported, it would be desirable to propose the mechanisms of the present acylsilane formation as being consistent with the features of these precedents. The reactions of isolable dialkylsilylene $\mathbf{1}$ with chloroalkanes afford rather unusual product mixtures depending on the substrates. For example, 1 reacts with 1-chlorobutane to afford solely the corresponding butylchlorosilane 4, while the reaction of 1 with $\mathrm{CCl}_{4}$ gives only dichlorosilane 5 (Equation (5)) [43]. When cyclopropylmethyl chloride is used as a substrate, the rather unusual 2:1 adduct 6 was obtained in addition to 5 (Equation (6)) [43]. 


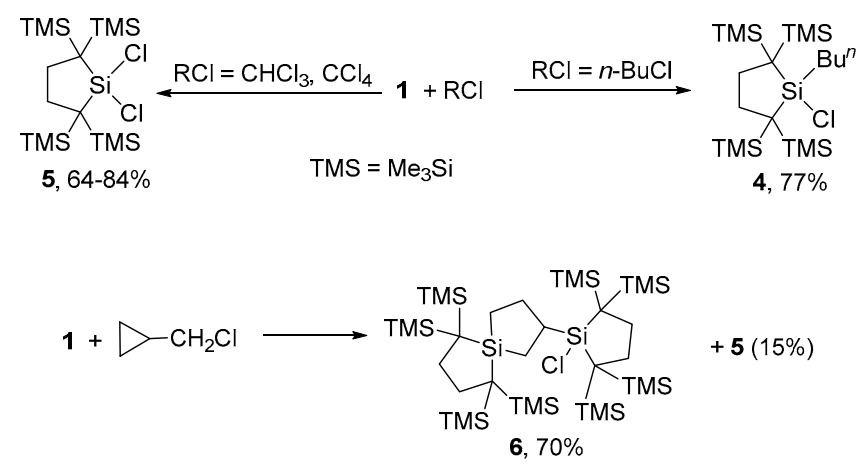

The diverse modes of the reactions between $\mathbf{1}$ with chloroalkanes [43] suggest a complex nature of the mechanisms. The reactions may be understood uniformly starting from initially formed Lewis acid-base complexes as shown in Scheme 1. From the complex, ionic cleavage of the $\mathrm{C}-\mathrm{Cl}$ bond followed by recombination would yield an alkylchlorosilane such as 4 [43]. The ionic mechanism is also applicable for the reaction of $\mathbf{1}$ with cyclopropylmethyl chloride, in which the intermediary cyclopropylmethyl cation or its equivalent 3-butenyl cation reacts with an extra silylene $\mathbf{1}$ forming 3-butenylsilyl cation and then finally 6; the 3-butenylsilyl cation would be stabilized by the coordination of the terminal $\pi$ bond. Chloroalkanes with less electron donating substituents like $\mathrm{CHCl}_{3}$ and $\mathrm{CCl}_{4}$ destabilize the carbocation intermediates and instead yield 5 after the homolysis of the $\mathrm{C}-\mathrm{Cl}$ bond [54].

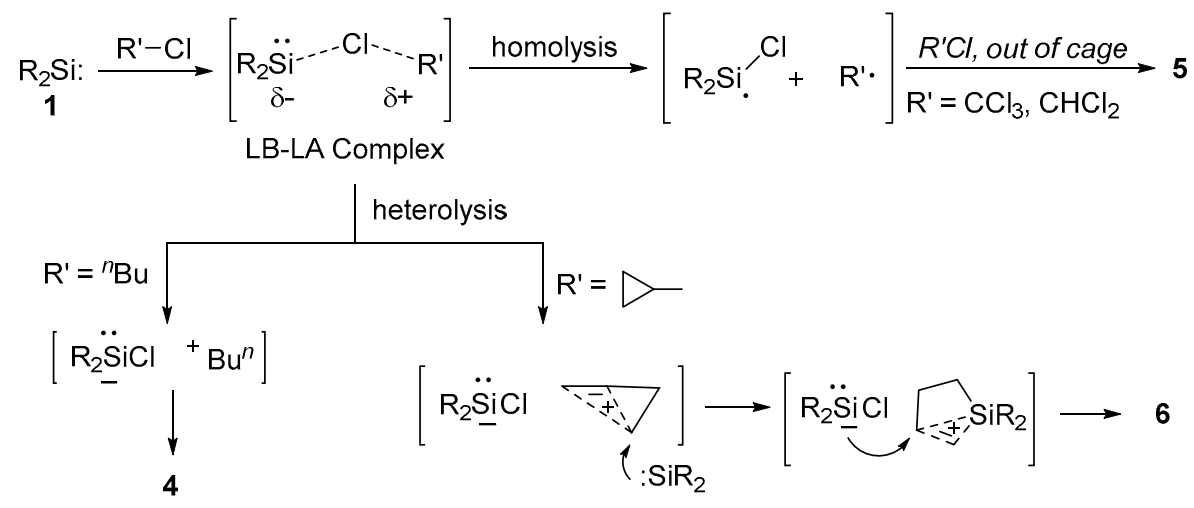

Scheme 1. Mechanisms of the reactions of $\mathbf{1}$ with chloroalkanes.

The aroylation of $\mathbf{1}$ may occur concertedly from the acylsilane-silylene complex as shown in Equation (7). Alternatively, the facile heterolysis of the $\mathrm{C}$ (carbonyl)- $\mathrm{Cl}$ bond from the complex followed by the coupling in cage may occur exclusively; the silylene serves as a Lewis acid to activate the $\mathrm{C}$ (carbonyl)-Cl bond (Equation (7)). The former concerted mechanism is preferred to the latter because of the similarity of the reactions with those of chlorislanes with $\mathbf{1}[50,51]$.

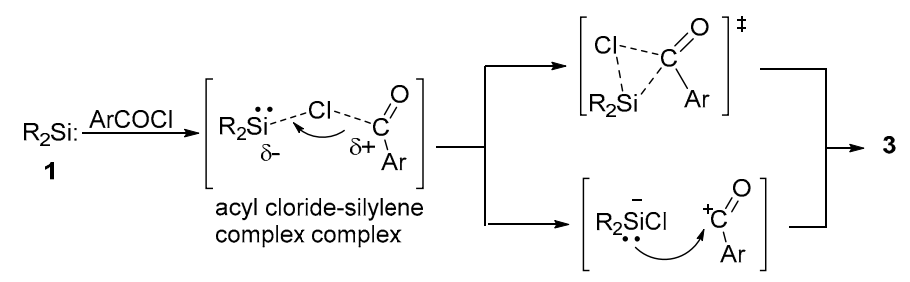


The insertion reactions of silylene 1 into the $\mathrm{Si}-\mathrm{Cl}$ bonds of chlorosilanes have been found to occur cleanly [49,50]; hence, the concerted mechanism via three-membered cyclic transition states has been proposed. The mechanism has been supported by the detailed DFT calculations [55-57].

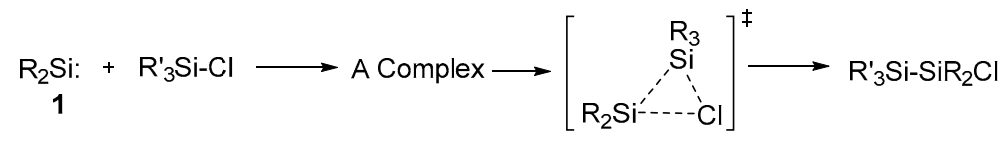

\section{Materials and Methods}

\subsection{General Procedures}

Manipulation of air-sensitive compounds was performed under a controlled dry argon atmosphere using standard Schlenk techniques. Tetrahydrofuran (THF), hexane, and toluene were distilled from sodium-benzophenone. All the other reagents were obtained from commercial suppliers and used without further purification. Dialkylsilylene $\mathbf{1}$ was prepared according to literature procedures [32]. ${ }^{1} \mathrm{H}-(400 \mathrm{MHz}),{ }^{13} \mathrm{C}-(100.6 \mathrm{MHz})$, and ${ }^{29} \mathrm{Si}-(79.5 \mathrm{MHz}) \mathrm{NMR}$ spectra were recorded on a Bruker AV-400 spectrometer at room temperature (Bruker, Rheinstetten, Germany), using $\mathrm{CDCl}_{3}$ as the solvent. Melting points are uncorrected. High-resolution mass spectra (HRMS) were recorded on a Bruker Daltonics Apex-III spectrometer (Bruker, Rheinstetten, Germany).

\subsection{Synthesis}

\subsubsection{Synthesis of $\mathbf{3 a}$}

A hexane solution of benzoyl chloride $(0.45 \mathrm{~g}, 3.2 \mathrm{mmol})$ was added to a solution of dialkylsilylene 1 (1.12 $\mathrm{g}, 3.0 \mathrm{mmol})$ in hexane at $-30{ }^{\circ} \mathrm{C}$. The reaction mixture was allowed to stir for $2 \mathrm{~h}$ at $0{ }^{\circ} \mathrm{C}$. The color of the solution changed from red to yellow. Then, the solvent was removed under vacuum. The resulting residue was purified by flash chromatography (Silica gel, 200-300 mesh; ethyl acetate/hexane, 1:300) to yield 3a as a yellow solid. Yield: $0.98 \mathrm{~g}$ (64\%). m.p. $152-154{ }^{\circ} \mathrm{C}$; ${ }^{1} \mathrm{H}-\mathrm{NMR}\left(400 \mathrm{MHz}, \mathrm{CDCl}_{3}\right): \delta 8.07(\mathrm{~d}, J=7.2 \mathrm{~Hz}, 2 \mathrm{H}, o-\mathrm{Ar}), 7.56(\mathrm{t}, J=7.2 \mathrm{~Hz}, 1 \mathrm{H}, p-\mathrm{Ar}), 7.49$ $(\mathrm{t}, J=7.2 \mathrm{~Hz}, 2 \mathrm{H}, m-\mathrm{Ar}), 2.14\left(\mathrm{~s}, 4 \mathrm{H}, \mathrm{CH}_{2}\right), 0.30\left(\mathrm{~s}, 18 \mathrm{H}, \mathrm{SiMe} e_{3}\right), 0.16\left(\mathrm{~s}, 18 \mathrm{H}, \mathrm{SiMe}_{3}\right) .{ }^{13} \mathrm{C}-\mathrm{NMR}$ $\left(101 \mathrm{MHz}, \mathrm{CDCl}_{3}\right): \delta 225.28(\mathrm{C}=\mathrm{O}), 138.90\left(\mathrm{C}_{\mathrm{Ar}} \mathrm{C}(\mathrm{O})\right), 133.22$ (p-Ar), 129.42 (o-Ar), 128.30 (m-Ar), 33.25 $\left.\left(\mathrm{CH}_{2}\right), 12.50\left(\mathrm{C}\left(\mathrm{SiMe}_{3}\right)_{2}\right), 4.27(\mathrm{SiMe})_{3}\right), 3.25(\mathrm{SiMe}) ;{ }^{29} \mathrm{Si}-\mathrm{NMR}\left(80 \mathrm{MHz}, \mathrm{CDCl}_{3}\right): \delta 27.84(\mathrm{SiCl}), 5.53$ ( $\left.\mathrm{SiMe}_{3}\right), 2.85$ ( $\mathrm{SiMe}_{3}$ ); HRMS(ESI) calculated for $\mathrm{C}_{23} \mathrm{H}_{45} \mathrm{ClOSi}_{5}$ : 513.2079, found 513.2078.

\subsubsection{Synthesis of $3 b$}

A hexane solution of $p$-methyl benzoyl chloride $(0.49 \mathrm{~g}, 3.2 \mathrm{mmol})$ was added to a solution of dialkylsilylene $1(1.12 \mathrm{~g}, 3.0 \mathrm{mmol})$ in hexane at $-30{ }^{\circ} \mathrm{C}$. The reaction mixture was allowed to stir for $2 \mathrm{~h}$ at $0{ }^{\circ} \mathrm{C}$. The color of the solution changed from red to yellow. Then, the solvent was removed under vacuum. The resulting residue was purified by flash chromatography (Silica gel, 200-300 mesh; ethyl acetate/hexane, 1:300) to yield $3 \mathrm{~b}$ as a yellow solid. Yield: $0.97 \mathrm{~g}(61 \%)$. m.p. $174-177^{\circ} \mathrm{C}$; ${ }^{1} \mathrm{H}-\mathrm{NMR}\left(400 \mathrm{MHz}, \mathrm{CDCl}_{3}\right): \delta 7.96$ (d, J = 7.2 Hz, 2H, o-Ar), 7.29 (d, J= 7.2 Hz, 2H, m-Ar), 2.43 (s, 3H, $\mathrm{Ar}-\mathrm{Me}$ ), 2.13 (s, 4H, CH ), 0.29 (s, 18H, SiMes), 0.17 (s, 18H, SiMes). ${ }^{13} \mathrm{C}-\mathrm{NMR}\left(101 \mathrm{MHz}, \mathrm{CDCl}_{3}\right): \delta$ $224.53(\mathrm{C}=\mathrm{O}), 144.13$ ( $\left.\mathrm{C}_{\mathrm{Ar}} \mathrm{C}(\mathrm{O})\right), 150.00,136.63$ (p-Ar), 129.59 (o-Ar), 128.98 (m-Ar), $33.24\left(\mathrm{CH}_{2}\right), 21.77$ $\left.(\mathrm{Ar}-\mathrm{Me}), 12.44\left(\mathrm{C}\left(\mathrm{SiMe}_{3}\right)_{2}\right), 4.28\left(\mathrm{SiMe}_{3}\right), 3.24(\mathrm{SiMe})_{3}\right){ }^{29} \mathrm{Si}-\mathrm{NMR}\left(79 \mathrm{MHz}, \mathrm{CDCl}_{3}\right): \delta 27.84(\mathrm{SiCl}), 5.47$ $\left(\mathrm{SiMe}_{3}\right), 2.81$ ( $\left.\mathrm{SiMe}_{3}\right)$; HRMS(ESI) calculated for $\mathrm{C}_{24} \mathrm{H}_{47} \mathrm{ClOSi}_{5}$ : 527.2225, found 527.2235.

\subsubsection{Synthesis of $3 c$}

A hexane solution of $p$-trifluoromethyl benzoyl chloride $(0.67 \mathrm{~g}, 3.2 \mathrm{mmol})$ was added to a solution of dialkylsilylene $\mathbf{1}(1.12 \mathrm{~g}, 3.0 \mathrm{mmol})$ in hexane at $-30{ }^{\circ} \mathrm{C}$. The reaction mixture was allowed to stir 
for $2 \mathrm{~h}$ at $0{ }^{\circ} \mathrm{C}$. The color of the solution changed from red to yellow. Then, the solvent was removed under vacuum. The resulting residue was purified by flash chromatography (Silica gel, 200-300 mesh; ethyl acetate/hexane, 1:300) to yield $3 \mathrm{c}$ as a yellow solid. Yield: $1.16 \mathrm{~g}$, (67\%). m.p. $160-163{ }^{\circ} \mathrm{C}$; ${ }^{1} \mathrm{H}-\mathrm{NMR}\left(400 \mathrm{MHz}, \mathrm{CDCl}_{3}\right): \delta 8.17(\mathrm{~d}, J=7.2 \mathrm{~Hz}, 2 \mathrm{H}, o-\mathrm{Ar}), 7.76(\mathrm{~d}, J=7.2 \mathrm{~Hz}, 2 \mathrm{H}, m-\mathrm{Ar}), 2.16(\mathrm{~s}, 4 \mathrm{H}$, $\left.\mathrm{CH}_{2}\right), 0.29$ (s, 18H, SiMes), 0.17 (s, 18H, SiMe 3$) .{ }^{13} \mathrm{C}-\mathrm{NMR}\left(101 \mathrm{MHz}, \mathrm{CDCl}_{3}\right): \delta 224.78(\mathrm{C}=\mathrm{O}), 140.87$ $\left(C_{\mathrm{Ar}}-\mathrm{C}(\mathrm{O})\right), 134.31(\mathrm{dd}, p-\mathrm{Ar}), 129.57(m-\mathrm{Ar}), 124.86(\mathrm{o}-\mathrm{Ar}), 123.61\left(\mathrm{dd}, J_{\mathrm{C}-\mathrm{F}}=271, \mathrm{CF}_{3}\right), 33.26\left(\mathrm{CH}_{2}\right)$, $12.61\left(\mathrm{C}\left(\mathrm{SiMe}_{3}\right)_{2}\right), 4.29\left(\mathrm{SiMe}_{3}\right), 3.22\left(\mathrm{SiMe}_{3}\right) .{ }^{29} \mathrm{Si}-\mathrm{NMR}\left(80 \mathrm{MHz}, \mathrm{CDCl}_{3}\right) \delta 27.83(\mathrm{SiCl}), 5.66\left(\mathrm{SiMe}_{3}\right)$, 2.94 ( $\mathrm{SiMe}$ ); HRMS(ESI) calculated for $\mathrm{C}_{24} \mathrm{H}_{44} \mathrm{ClF}_{3} \mathrm{OSi}_{5}$ : 581.1949, found 581.1952.

\subsection{X-ray Crystallography}

The diffraction data of 3a-3c were collected on a Bruker Smart Apex II CCD diffractometer with graphite-monochromated Mo K $\alpha$ radiation $(\lambda=0.71073 \AA)$. All of the data were collected at ambient temperatures, and the structures were solved via the direct method and subsequently refined on $F^{2}$ using full-matrix least-squares techniques (SHELXTL) [58]. Absorption corrections were applied empirically using the SADABS program [59]. The non-hydrogen atoms were refined anisotropically, and hydrogen atoms were located at calculated positions. A summary of the crystallographic data and selected experimental information is given in Table S1.

\section{Conclusions}

Isolable dialkylsilylene $\mathbf{1}$ was found to react with the $\mathrm{C}$ (carbonyl)-Cl bonds in aroyl chlorides 2 at low temperatures highly chemoselectively to give aroyl(chloro)silanes 3 ; the carbonyl groups in neither 2 nor 3 react with silylene $\mathbf{1}$. The structural analysis using NMR and X-ray crystallography indicate the lower field ${ }^{13} \mathrm{C}$-NMR resonance of the carbonyl carbon and longer $\mathrm{Si}-\mathrm{C}$ (carbonyl) bond distance than the standard values. The facile and highly selective nature of the reactions suggests that the insertion occurs concertedly from the initial Lewis acid-base complexes, similarly to that $\mathbf{1}$ into the $\mathrm{Si}-\mathrm{Cl}$ bonds in chlorosilanes. We are hoping the present synthetic methodology is applicable in general for a wide variety of silylenes. The silylenes should be however relatively long-lived and their reactions with the aroyl chlorides should be fast enough to prevent their oligomerization. Further works on the acylsilanes with unique electronic properties are under progress in our laboratory.

Supplementary Materials: Supplementary materials can be accessed at: http:/ /www.mdpi.com/1420-3049/21/ 10/1376/s1. Crystallographic information for compounds 3a-3c in CIF format and crystallographic tables.

Acknowledgments: This work was financially supported by the National Natural Science Foundation of China (Grant No. 21472032) and the Natural Science Foundation of Zhejiang Province (Grant No. LY17B010002).

Author Contributions: Z.L. conceived and designed the experiments; X.L., Q.L. and X.-Q.X. performed the experiments; X.-Q.X., X.L., Q.L., Z.L., G.L. and M.K. analyzed the data; X.-Q.X., Z.L. and M.K. wrote the paper. All authors have given approval to the final version of the manuscript.

Conflicts of Interest: The authors declare no conflict of interest.

\section{Appendix A}

Crystallography data (excluding structure factors) for the structures reported in this paper have been deposited with the Cambridge Crystallographic Data Center, CCDC 979677 (3a), 979676 (3b) and 979675 (3c). Copies of these data can be obtained free of charge on application to the Director, CCDC, 12 Union Road, Cambridge CB2 1EZ, UK (fax: +44-1223-336033; e-mail: deposit@ccdc.cam.ac.uk or http://www.http.ccdc.cam.ac.hk).

\section{References and Notes}

1. Brook, A.G. Keto Derivatives of Group IV Organometalloids. In Advances in Organometallic Chemistry; Stone, F.G.A., Robert, W., Eds.; Academic Press: Cambridge, MA, USA, 1969; Volume 7, pp. 95-155. 
2. Page, P.C.B.; Klair, S.S.; Rosenthal, S. Synthesis and chemistry of acyl silanes. Chem. Soc. Rev. 1990, 19, 147-195. [CrossRef]

3. Page, P.C.B.; Mckenzie, M.J.; Klair, S.S.; Rosenthal, S. Acyl Silanes. In The Chemistry of Organic Silicon Compounds; Rappoport, Z., Apeloig, Y., Eds.; John Wiley \& Sons: Hoboken, NJ, USA, 1998; pp. 1599-1665.

4. Cirillo, P.F.; Panek, J.S. Recent progress in the chemistry of acylsilanes. A review. Org. Prep. Proced. Int. 1992, 24, 553-582. [CrossRef]

5. Patrocínio, A.F.; Moran, P.J.; Brazil, J. Acylsilanes and their applications in organic chemistry. Chem. Soc. 2001, 12, 7-31. [CrossRef]

6. Zhang, H.-J.; Priebbenow, D.L.; Bolm, C. Acylsilanes: valuable organosilicon reagents in organic synthesis. Chem. Soc. Rev. 2013, 42, 8540-8571. [CrossRef] [PubMed]

7. Page, P.C.B.; McKenzie, M.J. Product Subclass 25: Acylsilanes. In Science of Synthesis; Fleming, I., Ed.; Thieme: Stuttgart, Germany, 2001; Volume 4, pp. 513-568.

8. Garrett, M.N.; Johnson, J.S. Product Subclass 4: Silicon Compounds. In Science of Synthesis Knowledge Updates 2012/2; Fleming, I., Ed.; Thieme: Stuttgart, Germany, 2012; Volume 4, pp. 1-85.

9. Boyce, G.R.; Grezler, S.N.; Johnson, J.S.; Linghu, X.; malinovski, J.T.; Nicewicz, D.A.; Satterfield, A.D.; Schmitt, D.C.; Steward, K.M. Silyl Glyoxylates. Conception and Realization of Flexible Conjunctive Reagents for Multicomponent Coupling. J. Org. Chem. 2012, 77, 4503-4515. [CrossRef] [PubMed]

10. Tsubouchi, A.; Sasaki, N.; Enatsu, S.; Takeda, T. Regio-and stereoselective preparation of (Z)-silyl enol ethers by three-component coupling using $\alpha, \beta$-unsaturated acylsilanes as core building blocks. Tetrahedron Lett. 2013, 54, 1264-1267. [CrossRef]

11. Honda, M.; Nakajima, T.; Okada, M.; Yamaguchi, K.; Suda, M.; Kunimoto, K.K.; Segi, M. Reaction of acylsilanes with $\alpha$-sulfinyl carbanions: Regioselective synthesis of silyl enol ethers. Tetrahedron Lett. 2011, 52, 3740-3742. [CrossRef]

12. Honda, M.; Iwamoto, R.; Nogami, Y.; Segi, M. Stereoselective tandem Aldol-Tishchenko reaction with acylsilanes. Chem. Lett. 2005, 34, 466-467. [CrossRef]

13. Zhang, H.J.; Becker, P.; Huang, H.; Pirwerdjan, R.; Pan, F.F.; Bolm, C. Photochemically induced silylacylations of alkynes with acylsilanes. Adv. Synth. Catal. 2012, 354, 2157-2161. [CrossRef]

14. Wu, L.; Li, G.X.; Fu, Q.Q.; Yu, L.T.; Tang, Z. Organocatalytic asymmetric Michael reaction with acylsilane donors. Org. Biomol. Chem. 2013, 11, 443-447. [CrossRef] [PubMed]

15. Chen, J.P.; Ding, C.H.; Liu, W.; Hou, X.L.; Dai, L.X. Palladium-catalyzed regio-, diastereo-, and enantioselective allylic alkylation of acylsilanes with monosubstituted allyl substrates. J. Am. Chem. Soc. 2010, 132, 15493-15495. [CrossRef] [PubMed]

16. Xin, L.H.; Nicewicz, D.A.; Johnson, J.S. Tandem Carbon-Carbon Bond Constructions via Catalyzed Cyanation/Brook Rearrangement/C-Acylation Reactions of Acylsilanes. Org. Lett. 2002, 4, 2957-2960.

17. Mattson, A.E.; Scheidt, K.A. Catalytic Additions of Acylsilanes to Imines: An Acyl Anion Strategy for the Direct Synthesis of $\alpha$-Amino Ketones. Org. Lett. 2004, 6, 4363-4366. [CrossRef] [PubMed]

18. Ruiz, J.; Karre, N.; Roisnel, T.; Chandrasekhar, S.; Gree, R. From Protected $\beta$-Hydroxy Acylsilanes to Functionalized Silyl Enol Ethers and Applications in Mukaiyama Aldol Reactions. Eur. J. Org. Chem. 2016, 773-779. [CrossRef]

19. Murthy, A.S.; Roisnel, T.; Chandrasekhar, S.; Gree, R. New $\beta$-Hydroxy Acylsilane-Derived Building Blocks and Their Use in the Synthesis of Oxygen-Containing Heterocycles. Synlett 2013, 24, 2216-2220. [CrossRef]

20. Brook, A.G.; Abdesaken, F.; Gutekunst, B.; Gutekunst, G.; Kallury, R.K. A Solid Silaethene: Isolation and Characterization. J. Chem. Soc. Chem. Commun. 1981, 191-192. [CrossRef]

21. Brook, A.G.; Nyburg, S.C.; Abdesaken, F.; Gutekunst, B.; Gutekunst, G.; Krishna, R.; Kallury, M.R.; Poon, Y.C.; Chang, Y.-M.; Wong-Ng, W. Stable Solid Silaethylenes. J. Am. Chem. Soc. 1982, 104, 5667-5612. [CrossRef]

22. Brook, A.G. Triphenylsilyl phenyl ketone. J. Am. Chem. Soc. 1957, 79, 4373-4375. [CrossRef]

23. Wittenberg, D.; Gilman, H. Reactions of Silyllithium Compounds with Derivatives of Carboxylic Acids. I. Triphenylsilyllithium and Acetyl Chloride. J. Am. Chem. Soc. 1958, 80, 4529-4531. [CrossRef]

24. Brook, A.G.; Duff, J.M.; Jones, P.F.; Davis, N.R. Synthesis of Silyl and Germyl Ketones. J. Am. Chem. Soc. 1967, 89, 431-434. [CrossRef]

25. Corey, E.J.; Seebach, D.; Freedman, R. Synthesis of $\alpha$-Silyl Ketones via 1,3-Dithianes. J. Am. Chem. Soc. 1967, 89, 434-436. [CrossRef] 
26. Chen, W.F.; Wang, L.L.; Li, Z.F.; Lin, A.Q.; Lai, G.Q.; Xiao, X.Q.; Deng, Y.; Kira, M. Diverse reactivity of an isolable dialkylsilylene toward imines. Dalton Trans. 2013, 42, 1872-1878. [CrossRef] [PubMed]

27. Liu, X.P.; Xiao, X.Q.; Xu, Z.; Yang, X.M.; Li, Z.F.; Dong, Z.W.; Yan, C.T.; Lai, G.Q.; Kira, M. Reactions of an Isolable Dialkylsilylene with Carbon Dioxide and Related Heterocumulenes. Organometallics 2014, 33, 5434-5439. [CrossRef]

28. Wang, L.L.; Chen, W.F.; Li, Z.F.; Xiao, X.Q.; Lai, G.Q.; Liu, X.P.; Xu, Z.; Kira, M. Reactions of an Isolable Dialkylsilylene with Aromatic Nitriles Providing a New Type of Heterosilole. Chem. Commun. 2013, 49, 9776-9778. [CrossRef] [PubMed]

29. Dong, Z.; Xiao, X.Q.; Li, Z.; Lu, Q.; Lai, G.; Kira, M. Elusive 2H-1,2-Oxasiletes Through Reactions of an Isolable Dialkylsilylene with Diazocarbonyl Compounds. Org. Biomol. Chem. 2015, 13, 9471-9476. [CrossRef] [PubMed]

30. Xiao, X.Q.; Dong, Z.; Li, Z.; Yan, C.; Lai, G.; Kira, M. 1,3-Diazasilabicyclo[1.1.0]butane with a Long Bridging N-N Bond. Angew. Chem. Int. Ed. 2016, 55, 3758-3762. [CrossRef] [PubMed]

31. Pinchuk, D.; Mathew, J.; Kaushansky, A.; Bravo-Zhivotovskii, D.; Apeloig, Y. Isolation and Characterization, Including by X-ray Crystallography, of Contact and Solvent-Separated Ion Pairs of Silenyl Lithium Species. Angew. Chem. Int. Ed. 2016, 55, 10258-10262. [CrossRef] [PubMed]

32. Kira, M.; Ishida, S.; Iwamoto, T.; Kabuto, C. The first isolable dialkylsilylene. J. Am. Chem. Soc. 1999, 121, 9722-9723. [CrossRef]

33. Kira, M. Isolable silylene, disilenes, trisilaallene, and related compounds. J. Organomet. Chem. 2004, 689, 4475-4488. [CrossRef]

34. Kira, M.; Ishida, S.; Iwamoto, T. Comparative chemistry of isolable divalent compounds of silicon, germanium, and tin. Chem. Rec. 2004, 4, 243-253. [CrossRef] [PubMed]

35. Kira, M.; Iwamoto, T.; Ishida, S. A Helmeted Dialkylsilylene. Bull. Chem. Soc. Jpn. 2007, 80, $258-275$. [CrossRef]

36. Kira, M. An isolable dialkylsilylene and its derivatives. A step toward comprehension of heavy unsaturated bonds. Chem. Commun. 2010, 46, 2893-2903. [CrossRef] [PubMed]

37. Kira, M. Reactions of a Stable Dialkylsilylene and Their Mechanisms. J. Chem. Sci. 2012, 124, $1205-1215$. [CrossRef]

38. Ishida, S.; Iwamoto, T.; Kira, M. Reactions of an Isolable Dialkylsilylene with Ketones. Organometallics 2010, 29, 5526-5534. [CrossRef] and references cited therein.

39. Ohshita, J.; Tokunaga, Y.; Sakurai, H.; Kunai, A. Reactions of lithium silenolates with acyl halides. First synthesis of di-and tetraacylsilanes. J. Am. Chem. Soc. 1999, 121, 6080-6081. [CrossRef]

40. Ohshita, J.; Kawamoto, H.; Kunai, A.; Ottosson, H. Formation of Acylsilenolates from Bis (acyl) trisilanes as the Silicon Analogues of Acylenolates. Organometallics 2010, 29, 4199-4202. [CrossRef]

41. Chieh, P.; Trotter, J. The structure of acetyltriphenylsilane. J. Chem. Soc. A 1969, 1778-1783. [CrossRef]

42. Ramsey, B.G.; Brook, A.; Bassindale, A.R.; Bock, H. $\sigma \rightarrow \pi^{*}$, A reassignment of the long wavelength uv transition in acyl-silanes and-germanes by photoelectron spectroscopy. J. Organomet. Chem. 1974, 74, C41-C45. [CrossRef]

43. Ishida, S.; Iwamoto, T.; Kabuto, C.; Kira, M. Unexpected reactions of an isolable dialkylsilylene with haloalkanes. Chem. Lett. 2001, 1102-1103. [CrossRef]

44. Ishikawa, M.; Nakagawa, K.-I.; Katayama, S.; Kumada, M. Photolysis of organopolysilanes. The reaction of photochemically generated trimethylsilyphenylsilylene with alkyl chlorides. J. Organomet. Chem. 1981, 216, C48-C50. [CrossRef]

45. Nakao, R.; Oka, K.; Dohmaru, T.; Nagata, Y.; Fukumoto, T. Chlorine abstraction from chloromethanes by dimethylsilanediyls. J. Chem. Soc. Chem. Commun. 1985, 766-768. [CrossRef]

46. Oka, K.; Nakao, R. Reaction of phenyl (trimethylsily) silylene with chloromethanes; insertion into the C-Cl bond and abstraction of chlorine and HCI. J. Organomet. Chem. 1990, 390, 7-18. [CrossRef]

47. Moser, D.F.; Bosse, T.; Olson, J.; Moser, J.L.; Guzei, I.A.; West, R. Halophilic Reactions of a Stable Silylene with Chloro and Bromocarbons. J. Am. Chem. Soc. 2002, 124, 4186-4187. [CrossRef] [PubMed]

48. Xiong, Y.; Yao, S.; Driess, M. Reactivity of a Zwitterionic Stable Silylene toward Halosilanes and Haloalkanes. Organometallics 2009, 28, 1927-1933. [CrossRef]

49. Ishida, S.; Iwamoto, T.; Kabuto, C.; Kira, M. A stable silicon-based allene analogue with a formally $s p$-hybridized silicon atom. Nature 2003, 421, 725-727. [CrossRef] [PubMed] 
50. Ishida, S.; Iwamoto, T.; Kabuto, C.; Kira, M. Insertion of a stable dialkylsilylene into silicon-chlorine bonds. Silicon Chem. 2003, 2, 137-140. [CrossRef]

51. Chen, Y.S.; Gaspar, P.P. Octakis(triemthylsilyl)cyclotetrasilane. A stable cyclotetrasilane from a silylene precursor. Organometallics 1982, 1, 1410-1412. [CrossRef]

52. Belzner, J.; Dehnert, U.; Ihmels, H.; Hübner, M.; Müller, P.; Uson, I. New Dichlorosilanes, Cyclotrisilanes, and Silacyclopropanes as Precursors of Intramolecularly Coordinated Silylenes. Chem. Eur. J. 1998, 4, 852-863. [CrossRef]

53. Belzner, J.; Dehnert, U.; Schar, D.; Rohde, B.; Muller, P.; Uson, I. Synthesis of di- and trisilanes with potentially chelating substituents. J. Organomet. Chem. 2002, 649, 25-42. [CrossRef]

54. Koecher, J.; Lehnig, M.; Neumann, W.P. Chemistry of heavy carbene analogs $\mathrm{R}_{2} \mathrm{M}(\mathrm{M}=\mathrm{Si}, \mathrm{Ge}, \mathrm{Sn}) .12$. Concerted and nonconcerted insertion reactions of dimethylgermylene into the carbon-halogen bond. Organometallics 1988, 7, 1201-1207. [CrossRef]

55. Lai, G.; Xu, Z.; Li, Z.; Jiang, J.; Kira, M.; Qiu, H. Stereoelectronic Substituent Effects on Silylene Insertion into the Si-Cl Bond. Organometallics 2009, 28, 3591-3593. [CrossRef]

56. Xu, Z.; Jin, J.; Li, Z.; Qiu, H.; Jiang, J.; Lai, G.; Kira, M. Remarkable Substituent Effects on the Activation Energy of Silylene Insertion into Silicon-Chlorine Bonds. Chem. Eur. J. 2009, 15, 8605-8612. [CrossRef] [PubMed]

57. Xu, Z.; Jin, J.; Zhang, H.; Li, Z.; Jiang, J.; Lai, G.; Kira, M. Insertion of Silylenes into Si-H and Si-Cl Bonds. Comparison of Mechanism and Substituent Effects. Organometallics 2011, 30, 3311-3317. [CrossRef]

58. SHELXTL version 6. 10; Bruker AXS Inc.: Madison, WI, USA, 2003.

59. Sheldrick, G.M. SADABS Program for Empirical X-ray Absorption Correction; University of Goettingen: Göttingen, Germany, 1996.

Sample Availability: Samples of the compounds 3a-3c are available from the authors.

(C) 2016 by the authors; licensee MDPI, Basel, Switzerland. This article is an open access article distributed under the terms and conditions of the Creative Commons Attribution (CC-BY) license (http://creativecommons.org/licenses/by/4.0/). 